Hispania, 2014, vol. LXXIV, $\mathrm{n}^{\circ}$. 247, mayo-agosto, págs. 385-410

ISSN: 0018-2141, e-ISSN: 1988-8368, doi: 10.3989/hispania.2014.012

\title{
EI linaje se transforma en casas: de los Fajardo a los marqueses de los Vélez y de Espinardo*
}

\author{
Juan Hernández Franco \\ Universidad de Murcia \\ Raimundo A. Rodríguez Pérez \\ Universidad de Murcia
}

RESUMEN: Este artículo intenta explicar el cambio en la forma de organización social y familiar de la aristocracia hispánica desde la baja Edad Media hasta el siglo XVIII. Se observa que algunos linajes tienen el poder suficiente para que de ellos surjan varias casas asentadas en el grupo aristocrático, a partir de la fundación de mayorazgos, matrimonios ventajosos y el favor regio. El estudio del linaje Fajardo alude a esa gran parte de familias de la grandeza que no crean líneas segundogénitas como estrategia expansiva. Fue la gracia real la que permitió la existencia de dos ramas: la casa de los Vélez, parientes mayores; y la de Espinardo, de origen segundón. Los servicios militares y cortesanos les darán una notable posición hasta el siglo XVII, pero a finales de la centuria la falta de matrimonios entre ambas hará que no exista una vía sucesoria alternativa y se diluyan en otras casas. La apuesta por la primogenitura de la casa de los Vélez y la pérdida de la varonía en la casa de Espinardo llevan

\footnotetext{
* Este trabajo forma parte de los proyectos de investigación HAR2010-2135-C05-01 Realidades familiares hispanas en conflicto: de la sociedad del linaje a la sociedad de los individuos, siglos XVII-XIX, financiado por el Ministerio de Economía y Competitividad; y 15300/PHCS/10 Nobilitas. Estudios y base documental de la nobleza del Reino de Murcia, siglos XV-XIX. Segunda fase: análisis comparativos, financiado por la Fundación Séneca, Agencia de Ciencia y Tecnología de la Región de Murcia. Siglas de archivos: AGS (Archivo General de Simancas); AHPM (Archivo Histórico de Protocolos de Madrid); AHPMu (Archivo Histórico de Protocolos de Murcia); ARChGr (Archivo de la Real Chancillería de Granada); ARChV (Archivo de la Real Chancillería de Valladolid); BL (British Library, Londres); BNE (Biblioteca Nacional de España, Madrid); SN-AHN (Sección Nobleza del Archivo Histórico Nacional, Toledo); RAH-SC (Real Academia de la Historia, Colección Salazar y Castro).
} 
a la desaparición del linaje. El apellido Fajardo perduró en otras casas principales sólo como un recuerdo de antiguas glorias.

PALABRAS CLAVE: Linaje; Casa; pariente mayor; ramas colaterales; tratadística nobiliaria

\section{Lineage becomes houses: from Fajardo to Marquises of los Vélez and Espinardo}

ABSTRACT: This article attempts to explain the change in the form of family and social organization of Hispanic aristocracy from the late Middle Age to the Eighteenth century. It is observed that some lineages have enough power for them arise several houses settled in aristocratic group, from the founding of primogeniture, advantageous marriages and royal favor. The stu$d y$ about lineage Fajardo refers much of 'grandeza' families that do not create second lines as expansion strategy. It was real grace that allowed the existence of two branches: the house of los Vélez, elderly relatives, and Espinardo, second son house. The military services and courtiers will give an important position until the Seventeenth century, but at the end of the century the lack of marriage between the two lines will be that there is no alternative means of inheritance and diluted in other houses. The commitment to the birthright of the house of los Vélez and the loss of the male line of the house of Espinardo involve the disappearance of the lineage. The surname Fajardo survived into other main houses just like a record of ancient glories.

KEY WORDS: Lineage; House; Elderly relative; Collateral branches; Nobility Literature.

\section{INTRODUCCIÓN}

La Historia Rerum Gestarum y la tratadística nobiliaria no están en plena conexión cuando valoran algunos de los principios que caracterizan al estamento que se encuentra en la cúspide de la sociedad antiguorregimental, es decir la nobleza. Tal hecho no debe ser visto como contradictorio, pues una parte notable de la historiografía reciente, a la luz de sus estudios, acepta y sostiene que el concepto «nobleza» se encuentra sumergido en un proceso de modificación que posiblemente los tratadistas no pudieron percibir en su totalidad, no obstante la importancia que entre ellos tuvieron las corrientes que, más allá de la sangre y el linaje, apostaron por la virtud y el mérito ${ }^{1}$. En consecuencia, no tiene por qué resultar extraño que, como intentamos demostrar

1 DEWALD, 2004: 40-48. BOURQUIN, 2002: 83-101. DONATI, 1995: 113-128. Para la nobleza española los tempranos trabajos de MARAVALL, 1986, vol. 2: 3-56. DOMÍNGUEZ ORTIZ, 1973: 161-166. Igualmente tratan sobre esta temática los recientes trabajos de ÁLVAREZ-OSSORIO ALVARIÑO, 2001: 39-60; 2006, 129-180. CARRASCO MARTÍNEZ, 1998, vol. 4: 231-271; 2009, vol. 1: 135-147. JIMÉNEZ MORENO, 2009, vol. 1: 209-256. 
a lo largo del presente artículo, los historiadores diferimos de los tratadistas al no considerar que linaje (del que por supuesto no podemos desprendernos para entender la ontología nobiliaria ${ }^{2}$ ) y casa sean la misma cosa. Cuestión que claramente afirmaban los últimos y, si no, recuérdese lo que escribió el emeritense Bernabé Moreno de Vargas, apoyándose a su vez en otros reputados tratadistas como Hernando de Mexía, Juan Arce de Otálora, Juan García de Saavedra, el doctor Salazar de Mendoza, y en los juristas Alfonso de Azevedo y Juan Gutiérrez ${ }^{3}$. Con rotundidad anotó el año 1636:

en España para dezir el linage de Lara, el linage de Osorio, dezimos la casa de Lara, la casa de Osorio, y así todos los demás linages nobles, como de los escritores e dellos se colige. De donde se viene a entender, que lo mismo es dezir hijosdalgo de solar conocido, que hijosdalgo de linaje conocido, porque linage, solar, y casa en este sentido significan una misma $\cos a^{4}$.

Nosotros consideramos que linaje deja de equivaler a casa y que ésta encierra un significado que, por un lado, es más restringido que el primero y, por otro, más amplio 5 . Más limitado pues ya no es esa familia extensa o grupo de descendencia unilineal con el que los tratadistas preferentemente definen al linaje. Por el contrario, casa reúne un grupo familiar más restringido, cada vez más cercano a lo que podríamos clasificar como familia nuclear. Y aunque no olvida y valora que desciende de reconocidos linajes y lo emplea como legitimador de su posición social privilegiada ${ }^{6}$ y emblema de su identi$\mathrm{dad}^{7}$, la casa atañe a los descendientes con lazos de sangre más estrechos, es decir, los nacidos en la casa; ciertamente no todos tienen iguales derechos, pero tampoco se ven sometidos a la estricta troncalidad que impera entre quienes asumen en su forma más determinante la ideología del linaje y su

2 BECEIRO PITA y CÓRDOBA DE LA LLAVE, 1990. BECEIRO PITA, 1990: 329349; 2010, 77-100. HEUSCH, 11 (2011).

3 MEXÍA, 1492. ARCE DE OTÁLORA, 1553. GARCÍA DE SAAVEDRA, 1622. SALAZAR DE MENDOZA, 1657. AZEVEDO, 1602. GUTIÉRREZ, 1730.

4 MORENO DE VARGAS, 1636: f. 28r.-v. En sentido similar al tratadista entienden esta vinculación entre linaje, casa y solar, quienes hacen las pruebas para conocer la nobleza y limpieza. Puede verse en Provança ante la Justicia de la Villa del Puerto de Santoña en nombre de Pedro de Maedo sobre su genealogía, nobleza y limpieza de linaje y de casas y solares conocidos de donde desciende. Villa del Puerto de Santoña, 1587, BL, Egerton, 1789.

5 Puede servir como ejemplo de esa concepción cada vez más reducida de parentesco, pero nunca desligada del origen de linaje, lo referido por Cristóbal de Mondragón para conseguir un hábito de caballero de orden militar. Consulta para un hábito a Cristóval de Mondragón, viznieto del Coronel Mondragón y sucesor en su casa, en consideración a los servicios de aquel y a los que su abuelo Alonso de Mondragón continúa haciendo en Flandes, 17 de julio de 1623, BL, Egerton, 318, doc. 31, f. 51 y siguientes.

6 GUILLÉN BERRENDERO, 2007: 123-120.

7 CARRASCO MARTÍNEZ, 2010: 165-176. 
estructuración en torno a un pariente mayor. Decimos también que casa es un concepto más amplio, pues la preocupación fundamental no es tanto la perduración del origen o sangre de un pariente mayor a través del trono principal ${ }^{8}$, cuanto la conservación y aumento de los bienes materiales y simbólicos de los que es heredera y poseedora, y que de forma no proporcional pertenecen y son distribuidos entre la mayor parte de los que la integran. Si un ejemplo valiese para verificar lo dicho, desde luego que lo tomaríamos de la Historia de la Casa de Herrasti (1750). Su autor, Juan Francisco de Paula Pérez Herrasti, nacido el año 1696, transmite perfectamente la idea que acabamos de exponer, presentándonos un linaje, que desde su aparición hacia finales del siglo XIV o principios del XV se ha desagregado en nueve casas, aunque reconoce que la primera es la «antigua», la fundada por «el Trono y cabeza de nuestra Línea y a quien conocemos por Pariente Mayor de ella por derivarse de él». Señala que todos los titulares de las casas siguen llevando el apellido que identifica con el linaje, y aunque hay pasajes de la obra en la que tiende a presentar como conceptos similares casa y linaje, en otros la distinción es evidenciable. En concreto, al hablarnos de la creación de la sexta casa, a cuyo frente estará Andrés Pérez de Herrasti Vera y Gadea (1624-1675), emplea la línea de descendencia para señalar que será «el primero de nuestro Linaje que tuvo ese nombre»; sin embargo, refiere Casa como el instrumento de la familia para reproducirse y poder continuar teniendo entre los miembros unidos por un parentesco más próximo los bienes que han ido adquiriendo9.

Esta falta de distinción que ya se vivía en la época, actualmente la sigue indicando Enrique Soria Mesa. Remarca que entre los temas de investigación futuros se encuentra desvelar exactamente qué es y cómo se transforma el linaje, así como su relación con casa y parentela. Con acierto sostiene que tenemos que «desvelar de una vez por todas el papel del linaje frente a conceptos tan relacionados como los de Casa, familia y parentela $\gg^{10}$.

Revisemos antes de pasar a exponer nuestra investigación directa sobre la familia extensa de los Fajardo, cómo ha ido la Historia - especialmente la historiografía europea y española - arrojando luz sobre la distinción entre linaje y casa. Lawrence Stone ${ }^{11}$, posiblemente fue el primero que, a partir de

8 Valgan como ejemplo de lo que puede ser linaje las dos propuestas siguientes. La primera corresponde a GUARDIOLA, 1591: 48. Éste suscribe que «en la cabeça de todo el linaje está y se demuestra el resplandor de aquella familia». La segunda es de SEVERIM DE FARIA, 2010: 81. Para este sacerdote y genealogista portugués linaje es «ordem de descendencia, que trazendo o seu principio de huma pessoa se vay continuando, e estendendo de filhos a netos, de maneira, que faz uma parentella ou linhagem; a qual da antiguidade, e clareza das cousas feitas he chamado nobre».

9 PÉREZ DE HERRASTI, 1750: 131-141.

10 SORIA MESA, 2009: 222.

11 STONE, 1989: 78-82. 
sus amplios conocimientos sobre nobleza y familia, señaló tal cuestión. La explica a partir de lo que denomina «decadencia del parentesco», o lo que es lo mismo, la transformación de la familia de linaje abierto en familia de linaje cerrado, lo que motiva que las relaciones de parentesco amplio, tan común entre los viejos clanes y linajes, devenga y se limite a los parientes más cercanos, a un núcleo formado por padres e hijos, y rara vez el tío o tía soltero que apoya y trabaja para el núcleo; aunque ciertamente admite (en el presente trabajo esta realidad también se percibe), Sin creer por ello que haya contradicciones, sino complejidad, que lo que existió fue un desgaste del parentesco, aunque los lazos familiares extensos siguieron desempeñando un papel importante dentro de la vida de la familia hasta bien entrado el siglo XIX ${ }^{12}$.

Para Stone la causa principal de esta decadencia del parentesco se encuentra en la emergencia del Estado moderno, enemigo general de los valores de los grupos familiares extensos, por cuanto podían limitar su poder o, mejor dicho, sus poderes. Y esa propuesta, fue perfectamente desarrollada por la historiadora Sharon Kettering a lo largo de su obra sobre corte, patronos y clientelas en la Francia del siglo XVII. Aunque la casa no sea el tema central de su trabajo - que como se recordará incide en la capacidad del embrionario «estado burocrático» para ampliar progresivamente su control sobre provincias desleales y nobles a través de la figura de los gobernadores territoriales y de los notables regionales dependientes de los ministros de la corona-, cuando trata de la misma, señala que precisamente el incipiente desarrollo del «estado burocrático» provoca la reducción del tamaño de la casa real. El efecto es similar entre las casas nobiliarias, que igualmente reducen su dimensión y la concretan al parentesco más próximo y a los agregados domésticos más leales y que mejor desempeñan su servicio ${ }^{13}$.

La propuesta de Kettering coincide, en lo relativo al papel de la corte en la reducción, lustre e influencia social y económica de la casa, con la que ha efectuado Kate Mestres para la nobleza inglesa. Sin embargo, esta historiadora no trata de forma relacional la cuestión linaje-casa, y llega a la conclusión de que a finales del siglo XVI, tras el esfuerzo de los Tudor para fidelizar a la aristocracia inglesa, la casa que con anterioridad (1200-1480) había sido una especie de pequeña corte, comienza a disolverse, a desaparecer - exactamente su conclu-

12 La teoría del desgaste del parentesco extenso, no tanto su desaparición, se confirma en el trabajo de GRASSBY, 2001. Los comerciantes londinenses del siglo XVII debían ser un ejemplo perfecto de esta modernización social que supone la reducción de las relaciones de parentesco, pero Grassby indica que aun registrándose una modernización del modelo familiar, también se constata que el éxito de las transacciones descansa en las relaciones de parentesco y la confianza que éstas proporcionaban.

13 KETTERING, 1986; 2001; 16/2 (Tempe, 1989): 408-435; 20 (Tempe, 1997): 55-85; 21/3 (Oxford, 2007): 269-288. 
sión es «The demise of the Household»- Aunque señala, y esto es sumamente interesante, pues coinciden las circunstancias de la casa en Inglaterra con la de otros espacios y sociedades nobiliarias europeas, que desciende notablemente el número de miembros (incluidos agregados domésticos) que la integran ${ }^{14}$.

Si miramos a los reinos de la Península Ibérica, y en concreto a Portugal, los excelentes trabajos de N. G. Monteiro y M. Soares da Cunha inciden en las cuestiones que estamos señalando. Es decir, por un lado, la pérdida de relieve del linaje frente al concepto casa y, de otro, la disminución del número de integrantes de la casa; aunque a la vez - dentro de las prácticas de control y alianza de la Monarquía con el grupo privilegiado-, debemos subrayar también el aumento del número de casas nobiliarias, hasta el punto de presentar a la sociedad portuguesa como una sociedad de «Casas». En esa sociedad de casas, por tal se entiende un «conjunto coerente de bens simbólicos e materiais a cuya reprodução alargada estavam obrigados todos os que nela nasciam ou dela dependiam». Tanto peso había adquirido, pues, la casa dentro de la sociedad de élites, que finalmente el linaje u origen remoto es, apenas, un elemento integrante de la identidad de la casa ${ }^{15}$.

\section{LA CASA COMO FUNDAMENTO DE LA ARISTOCRACIA HISPÁNICA}

Posiblemente en Castilla no se llegue a ese extremo, pero los estudios realizados en las dos últimas décadas señalan que el linaje se desvaneció a favor de una identidad más sentida de la familia noble con la casa. Pues, sin romper abiertamente con el origen, permitía adaptarse a una época de cambio dentro del grupo nobiliario en el que la dependencia de la casa real, la aparición de nuevas vías de acceso a la nobleza y un sentido más próximo de parentesco y obligaciones en torno al mismo, son realidades sumamente influyentes.

Desde las postrimerías de la Edad Media en Castilla, los linajes más poderosos habían dado lugar a varias casas, a partir de mayorazgos creados para hijos segundones e ilegítimos, en un proceso que se prolongará y afianzará durante los siglos XVI y XVII. Algunas de esas nuevas casas pronto se situaron entre las más ricas y prestigiosas de la grandeza hispánica, acumulando

14 MESTRES, 1988: 183-193. La tesis de Mestres sobre el gran tamaño, fortaleza y amplias relaciones de parentesco que aglutina la casa en Inglaterra, hasta comienzos del siglo XVI, ha sido reiterada por GRACE, 35 (Southampton, 2009): 189-203.

15 MONTEIRO, 1998; 2007; 12 (Lisboa, 1993): 43-63; 46 (París, 1999): 185-210; 2001: 17-37; 1995: 256-284. CUNHA, 2000. CUNHA y MONTEIRO, 2010: 47-75. SALVADO, 9/2 (2011). 
títulos y señoríos. Junto al mayorazgo ${ }^{16}$, universalizado, a partir de 1505 con las Leyes de Toro, las dotes y particiones de bienes contribuyen a cohesionar la jerarquía de los linajes mediante el reparto de las riquezas entre los miembros del grupo familiar, primando la primogenitura y la varonía. Entre esos linajes «fecundos» pueden citarse los Fernández de Córdoba (casas de Priego, Cabra, Comares y Alcaide de los Donceles), Toledo (Alba, Oropesa, Villafranca), Zúñiga (Béjar, Miranda, Monterrey), Manrique (Nájera, Paredes, Osorno), Pacheco-Girón (Villena, Osuna, Villanueva del Fresno, Puebla de Montalbán), Mendoza (Infantado, Monteagudo, Mondéjar, Mélito, Cenete) y Silva (Cifuentes, Pastrana). Es decir, esta emergencia de ramas segundonas pronto separadas del tronco principal del linaje implica tanto a algunas de las familias más antiguas de la nobleza castellana, emparentadas con la realeza (Mendoza, Manrique), como a otras de origen foráneo, concretamente portugués (Pacheco, Silva), encumbradas merced al favor regio.

Los monarcas, ya sean Trastámaras o Austrias, actuarán como árbitros en la política matrimonial aristocrática, intentando evitar que una sola casa acumulase demasiado poder, y favoreciendo el enlace de viejos linajes con familias más humildes, pero sólidamente asentadas en la corte como burócratas y criados. Ilustres apellidos, vinculados a la guerra (Manriques, Fajardos), no dudarán en unirse a familias notoriamente manchadas por la sangre conversa (como los marqueses de Moya), o bien a familias de origen modesto (Chacón, De la Cueva y Cárdenas). Dichos enlaces desiguales afianzan el control del soberano sobre la aristocracia y proporciona a las casas más antiguas una posición más sólida en la corte, en tanto que las casas menos ilustres se unen a la vieja nobleza de sangre.

La concesión de nuevos títulos y señoríos no acabó con el fin de la Reconquista ya que el cursus honorum cortesano y la milicia dieron oportunidad a las grandes casas de consolidar su posición e, incluso, mejorarla. Como paradigma de casa que acumuló títulos y señoríos en diversos reinos bajo autoridad de los Habsburgo (Castilla, Aragón, Portugal, Nápoles y Cerdeña) destacan los duques de Pastrana, descendientes del príncipe de Éboli, Ruy Gómez de Silva ${ }^{17}$. El talento para las armas, la diplomacia y el servicio palatino determinará que algunos individuos, en muchos casos segundones o espurios, encumbren a su estirpe por encima de la de sus parientes mayores. El caso paradigmático es el del conde-duque de Olivares, titular de una línea segundona de la casa más importante de la grandeza de España: los duques de Me-

16 CLAVERO, 1974: 123-180.

17 Las disputas intrafamiliares por tan inmensa herencia enfrentaron a la rama primogénita (duque de Pastrana) con la segundogénita (conde de Salinas). TERRASA LOZANO, 2012: 157-181. 
dina Sidonia ${ }^{18}$. Sin olvidar al virrey de Nápoles Pedro de Toledo, segundón de la casa de Alba, que llegó al marquesado de Villafranca por vía matrimonial y, dada su relevancia en Italia, casó a una de sus hijas con el cabeza de la familia Médicis ${ }^{19}$. Además de individuos que por sí solos crean una casa propia o la refundan, también hay ejemplos colectivos, en los que una rama menor acaba - con el paso de varias generaciones - superando en riqueza y prestigio a la más antigua. Este fue el caso de los condes de Ureña ${ }^{20}$ (futuros duques de Osuna), descendientes del hermano menor de don Juan Pacheco, I marqués de Villena; así como de los condes de Cabra y duques de Sessa, que alcanzaron mayor relevancia que la casa de Aguilar, línea matriz de los Fernández de $\mathrm{Có}_{\text {rdoba }}{ }^{21}$; y los citados Pastrana, que superarán con creces a la más antigua casa de Cifuentes (linaje Silva), también con solar portugués.

Estos éxitos y fracasos, altibajos derivados de la cercanía al rey o a su privado, presentan ejemplos de recuperación del poder. Fue el caso de los marqueses de Villena, alejados del espacio áulico durante un siglo, tras su defensa de Juana la Beltraneja en la guerra civil castellana, que, sin embargo, a través de su unión con lo más selecto de la nobleza castellana y portuguesa ${ }^{22}$ (Oropesa, Braganza), volverán a gozar de la gracia regia, ocupando puestos decisivos en la administración, como algunos virreinatos italianos y america$\operatorname{nos}^{23}$.

Matrimonios, mayorazgos y gracia real determinan la evolución de los grandes linajes aristocráticos hacia casas concentradas en su parentela más cercana, incluso en la ilegítima, por encima de cualquier legendario antepasado común, es decir del linaje ${ }^{24}$. Ahora bien, la multiplicación de líneas segundonas que alcanzan el éxito no fue una norma, ni siquiera entre la grandeza, más bien una excepción, restringida a aquellas familias que dispusieron de mayores recursos patrimoniales (vía compra, concesión regia o absorción de ramas colaterales) y desarrollaron acertadas estrategias matrimoniales, a menudo endogámicas ${ }^{25}$. Conforme pasen los años, la aristocracia verá como el precio de las dotes, y en menor medida las arras, aumenta vertiginosamente,

18 ELLIOTT, 1990: 29-73.

19 HERNANDO SÁNCHEZ, 1994: 117-150.

20 ATIENZA HERNÁNDEZ, 1987.

21 QUINTANILLA RASO, 1996: 79-110. MOLINA RECIO, 2004.

22 Tanto los Villena como los Oropesa o los Medina Sidonia casaron con los Braganza, dado que los monarcas españoles pretendían consolidar la débil fidelidad de la principal casa lusa, algo que no dio resultados positivos. CUNHA, 64/216 (Madrid, 2004): 39-62.

23 El título de Villena era realmente simbólico, pues tras la llamada Guerra del Marquesado (1476-1480) los Pacheco pierden casi todo ese inmenso señorío y fijarán su residencia en Escalona. MOLINA PUCHE y ORTUÑO MOLINA, 2009: 135-142.

${ }^{24}$ HERNÁNDEZ FRANCO y MOLINA PUCHE, 66 (Valencia, 2010): 3-22.

25 QUINTANILLA RASO, 2009: 89-120. 
dificultando el acceso al mercado matrimonial de buena parte de sus hijos. La necesidad de obtener dispensas papales que salvasen los cercanos grados de parentesco no solía ser un obstáculo, si bien se produjeron rechazos por parte de la curia ${ }^{26}$. Otro obstáculo que también dio quebraderos de cabeza a la aristocracia fue el papel del soberano, que castigaba con cárcel y destierro las bodas sin su consentimiento, así como las promesas de matrimonio rotas a alguna dama de la corte ${ }^{27}$. Pero sobre todo serán las costosas dotes de las hijas las que hagan que los grandes negocien concienzudamente los enlaces, convertidos en acuerdos económicos, pero también políticos y territoriales ${ }^{28}$.

La importancia de la casa por encima del linaje se deduce del trabajo encargado a los tratadistas nobiliarios durante el siglo XVII. Debido a la inflación de títulos y honores, las casas más ilustres necesitan reivindicar su primacía y, por tanto, su condición de «auténticas» o al menos «primeras» casas $^{29}$. El más ilustre genealogista, don Luis de Salazar y Castro, denomina sus obras utilizando el término «Casa», a la hora de abordar las historias de los Silva, Lara, Haro o Fajardo, entre otras. La intencionalidad del autor y de sus interesados mecenas es alabar a la casa, sin renunciar a la búsqueda de los ancestros - el linaje - pero centrándose en la línea de primogenitura para glosar méritos y virtudes, tal y como ha señalado David García Hernán ${ }^{30}$.

La no emergencia de líneas segundogénitas desgajadas de la principal fue habitual entre casas de la grandeza. Pruebas destacadas encontramos en los condes de Oñate o en los duques de Arcos y Alcalá ${ }^{1}$. Se trata de casas centradas en asegurar la continuidad y mejorar la posición de la rama primogénita, que incluso tuvieron que recurrir a la legitimación de algún vástago ilegítimo ante la falta de descendientes, como sucede con los Ponce de León (casa de Arcos) en $1476^{32}$. En cuanto a los Vélez de Guevara, la falta de descendencia de la línea de primogenitura (condes de Oñate) les llevó a unirse con la rama segundona (señores de Salinillas) para evitar la desaparición de la ca$\mathrm{sa}^{33}$. Por tanto, la línea menor se pone al servicio de la mayor.

Familias mucho menos ilustres a priori, en tanto que no revestidas del carácter militar o de la sangre más ilustre, como los Cárdenas, merced al servi-

26 Fue el caso del futuro III marqués de los Vélez, que en 1568 no obtuvo la dispensa papal que salvara el tercer y cuarto grado de consanguinidad cuando intentaba unirse a la hermana menor de su primera esposa, Magdalena Girón, de la casa de Osuna. MARAÑÓN, 2005: 136-142.

27 ATIENZA HERNÁNDEZ y SIMÓN LÓPEZ, 1 (Murcia, 1989): 31-52.

28 BECEIRO PITA y CÓRDOBA DE LA LLAVE, 1990: 170-197.

29 DOMÍNGUEZ ORTIZ, 1973: 77-78.

30 GARCÍA HERNÁN, 15 (Madrid, 2011): 28-38.

31 BECEIRO PITA, 1998. CARRIAZO RUBIO, 2002. LADERO QUESADA, 1998.

32 SORIA MESA, 2007: 193.

33 MINGUITO PALOMARES, 2002: 22-30. 
cio palatino acumularán tal cantidad de riquezas y patrimonio que fundarán varios mayorazgos, los cuales junto al título de duques de Maqueda, pronto les sitúan a la par que los antiguos ricoshombres, de hecho enlazan con familias del mayor abolengo, como los Enríquez ${ }^{34}$. Algo similar ocurre con otros ínclitos criados de los Reyes Católicos, como los marqueses de Moya y los Chacón, estos últimos condes de Casarrubios del Monte desde 1599. La privanza es la clave de ascensos tan fulgurantes y crea fidelidades hacia los reyes, especialmente en épocas de debilidad de su autoridad, con motivo de guerras, revueltas nobiliarias o minorías de edad. El monarca se apoya en los aristócratas para gobernar y, cuando el privado de turno no tiene tal rango, se le conceden títulos y mercedes que lo encumbran (fue el caso de Francisco de los $\operatorname{Cobos}^{35}$ ), permitiendo que él y sus familiares casen con las casas más poderosas, sin cuyo apoyo era difícil mantenerse en el poder ${ }^{36}$. Esto queda de manifiesto con la caída en desgracia de Álvaro de Luna, Lerma y algunos de los últimos validos del XVII, como Valenzuela y don Juan José de Austria, y no se diferencia demasiado de lo que ocurre en Francia o Inglaterra ${ }^{37}$.

\section{LOS FAJARDO: LA APUESTA POR LA PRIMOGENITURA Y EL ASCENSO DE LOS PARIENTES MENORES}

El salto de los Fajardo al selecto grupo de los ricoshombres castellanos, según la denominación anterior a la de grandes de España (de origen confuso e idealizado) ${ }^{38}$, se produce con su consolidación en el adelantamiento y capitanía mayor del reino de Murcia, durante la segunda mitad del siglo XV, de la mano de don Pedro Fajardo Quesada ${ }^{39}$. Dicho cargo de adelantado — que ostentaban desde finales del siglo XIV - era uno de los pocos que para entonces seguía teniendo auténtico significado militar, debido a la estratégica frontera con el reino nazarí de Granada. Será durante ese período cuando los Fajardo comiencen a contraer nupcias con familias aristocráticas (Manrique, Cardona, Corella), de un estatus superior al suyo. Con ello, logran afianzar su dominio sobre el reino de Murcia, especialmente sobre las numerosas encomiendas santiaguistas, y se insertan en los complejos y cambiantes juegos de

34 PALENCIA HERREJÓN, 29 (Sevilla, 2002): 337-356.

35 KENISTON, 1980. MOLAS RIBALTA, 2009: 147-162.

36 TOMÁS Y VALIENTE, 1982. BENIGNO, 1992. GARCÍA GARCÍA, 28 (Valencia, 1997): 113-125.

37 ELLIOTT y BROCKLISS, 1999.

38 SORIA MESA, 2001: 619-636. QUINTANILLA RASO, 2006: 19-100.

39 TORRES FONTES, 1953. 
alianzas en la corte castellana ${ }^{40}$. Sin embargo, el éxito del adelantado Fajardo Quesada no fue completo, al no tener descendiente varón que le sobreviviese. El peligro de desaparición de su estirpe quedó solventado con el matrimonio de su hija mayor, Luisa Fajardo Manrique, con Juan Chacón, hijo de uno de los criados más cercanos a Isabel la Católica, Gonzalo Chacón ${ }^{41}$. Los Chacón, de condición social más baja, aseguraban una jefatura transitoria de la casa y que el apellido Fajardo continuase como principal en el primogénito. El adelantado Juan Chacón fue el fundador del mayorazgo de los Fajardo ${ }^{42}(1491)$ y sentó las bases del estado señorial en el reino de Granada. Asimismo, renovó la alianza de su suegro con los Manrique ${ }^{43}$, a través de los enlaces de varios de sus hijos - entre ellos el primogénito-, y unió a otros dos —entre ellos el segundogénito y heredero del mayorazgo de los Chacón - con la casa de los señores de la Puebla de Montalbán ${ }^{44}$, rama segundona del marqués de Villena. Por tanto, a la vez que asegura la supervivencia de su familia política, Chacón refuerza su propia casa, uniéndola a los Fajardo y los Pacheco, apellidos de mayor lustre.

Todos los marqueses de los Vélez, hasta la extinción biológica de la casa a inicios del siglo XVIII, casaron con hijas de familias aristocráticas. Pero no

40 RODRÍGUEZ LLOPIS, 12 (Murcia, 1996): 57-90.

41 Escritura otorgada por Pedro Fajardo, adelantado mayor de Murcia, señor de Cartagena, por doña Leonor Manrique, su mujer, y por la hija de ambos, doña Luisa Fajardo, de una parte; y por Bartolomé Maraver de Zafra, enviado especial de los Reyes Católicos para firmar esta capitulación, en nombre de Juan Chacón, hijo de Gonzalo Chacón, para el matrimonio de dicho Juan con la mencionada doña Luisa. Va incluida la cédula de los Reyes Católicos, Fernando V y doña Isabel I, ordenando se verifiquen estas capitulaciones. 11 de mayo de 1477, RAH, SC, M. 8, f. 101r.-106r.

42 Escritura de fundación de mayorazgo sobre ciertas villas y otros derechos de la casa de los señores de Fajardo, otorgada por Juan Chacón, adelantado mayor de Murcia, en conformidad con la disposición testamentaria de su mujer Luisa Fajardo, llamando a su goce a sus hijos y descendientes con la condición de usar su apellido y escudo de armas de los Fajardo. 6 de abril de 1491, SN-AHN, Osuna, C. 35, D. 28, f. 18-19.

43 Capitulaciones que se hicieron para el matrimonio de Rodrigo Manrique de Lara y Acuña, III conde de Paredes de Nava, y de su hermana, doña Magdalena Manrique de Lara y Acuña, con doña Isabel Chacón y con Gonzalo, II señor de Casarrubios [será su hermano mayor, Pedro Fajardo Chacón, quien casará con Magdalena], su hermano, hijos ambos de Juan Chacón, adelantado y capitán mayor del reino de Murcia. Córdoba, 10 de diciembre de 1491, RAH, SC, M. 1, f. 80v.-82r.

${ }_{44}$ Escritura otorgada por Gonzalo Chacón, mayordomo mayor de la reina doña Isabel I, la Católica, y Juan Chacón, adelantado mayor de Murcia, señor de Cartagena, su padre, de una parte; y de la otra Alonso Téllez-Girón, II señor de la Puebla de Montalbán, comendador de Medina de las Torres, en la Orden de Santiago, para el matrimonio de dicho Gonzalo y de su hermana doña Leonor Chacón, con doña Francisca de Guevara, después señora de Casarrubios del Monte, y con Juan Pacheco, hermanos, respectivamente, e hijos, estos últimos, de dicho Alonso. 18 de diciembre de 1502, RAH, SC, M. 23, f. 134v.-135v. 
ocurrió lo mismo con los hijos segundones, que durante gran parte del siglo XVI se vieron relegados a la soltería, o bien a enlazar con ramas segundonas de casas tituladas, especialmente en el caso de las hijas. Lo cierto es que tanto los primogénitos como casi todos sus hermanos menores se unieron con familias ajenas al reino de Murcia, donde tenían su base patrimonial, por ser un territorio sin nobleza titulada, aparte de la propia casa de los Vélez. En el otro baluarte de su poder señorial, el oriente granadino, sí encontraron cónyuges diversas hijas de los Vélez, entre algunas familias con señoríos vecinos al marquesado, como los señores de Gor y, sobre todo, los Enríquez de Guzmán (señores de Orce, Galera y Filabres, además de factótum de la ciudad de Baza) ${ }^{45}$. Será ya en el siglo XVII cuando las hijas de los marqueses de los Vélez - cortesanos destacados y comprometidos servidores de los dos últimos Habsburgos- casen con herederos de importantes títulos, como el conde de Benavente, debido a las uniones endogámicas entre Fajardos y Pimenteles a lo largo de tres generaciones, desde finales del siglo XVI hasta el primer tercio del XVII ${ }^{46}$. En suma, el elevado precio de dotes y arras, máxime cuando se quería unir a las hijas con herederos de casas de la grandeza, así como la necesidad de afianzar alianzas territoriales que consoliden su poder sobre la zona oriental del reino granadino, marcarán la pauta de las estrategias matrimoniales de la casa de los Vélez.

En cualquier caso, el poder señorial sobre los reinos de Murcia y Granada, y a partir del primer tercio del siglo XVII en los estados catalanes heredados de los Requesens (convertidos en marquesado de Martorell desde $1627^{47}$ ), no debe ocultar la verdadera vocación de los Vélez desde el último tercio del siglo XVI: el servicio regio, o lo que es lo mismo la corte ${ }^{48}$. El espacio áulico era el verdadero leit motiv de la aristocracia, incluso en períodos de alejamiento forzado, por falta de acceso a la gracia regia o desavenencias con el privado de turno. Será en la corte donde la casa pueda acrecentar su prestigio, mediante gracias, cargos y honores. Esto fue algo común entre la inmensa mayoría de casas tituladas hispánicas, y en el caso de los Vélez tuvo que ver además con el final de su influencia sobre la ciudad de Murcia, tras su liderazgo comunero ${ }^{49}$. En cuanto a los señoríos, los Fajardo tampoco revivieron

45 Memorial de Fernando Fajardo y Requesens, VI marqués de los Vélez, en el que hace una relación de los servicios de sus antepasados y pide a Carlos II, rey de España, que la Grandeza de España de su casa sea considerada de primera clase. Borrador, RAH, SC, D. 39, f. 49v.-51v.

46 Capitulaciones matrimoniales de Doña Mencía Requesens y Zúñiga con el Conde de Benavente. Madrid, 18 de julio de 1581, AHPM, Prot. 985, f. 1.288 y siguientes.

47 NEGRE PASTELL, 10 (Gerona, 1955): 105.

48 RODRÍGUEZ PÉREZ, 2011.

49 OWENS, 1980. HERNÁNDEZ FRANCO y JIMÉNEZ ALCÁZAR, 23 (Granada, 1996): 171-187. COOPER, 56/193 (Madrid, 1996): 467-495. ANDÚJAR CASTILLO, 2001, vol. 2: 43-62. 
su esplendor como señores de vasallos, sobre todo por los numerosos pleitos con la oligarquía de la villa de Mula $^{50}$ (capital de sus estados murcianos) y la expulsión de los moriscos de sus señoríos granadinos, que quedaron prácticamente despoblados a partir de 1571, y que con la repoblación cristiano vieja trajeron vasallos mucho menos dóciles y que debían cargar con cargas fiscales menos onerosas ${ }^{51}$. Este panorama no implica, sin embargo, un desinterés de los Fajardo por el gobierno de su casa y estados, revitalizado en el siglo XVII con el encargo de un Libro Becerro para el mejor funcionamiento de la administración señorial $^{52}$, aunque desde la lejanía de la corte o diversos virreinatos.

El linaje Fajardo, por tanto, no pertenece al reducido grupo que consigue desgajar por iniciativa propia a varias casas de su tronco. De hecho ninguno de sus parientes mayores creó mayorazgos para algún segundón o bastardo. Aquellos que lograron vincular patrimonio, incluso obteniendo título nobiliario para sí mismo o para sus hijos, fue gracias a los bienes recibidos por vía matrimonial y a los destacados servicios cortesanos y militares ${ }^{53}$. Y ello a pesar de que los marqueses de los Vélez pertenecían al sector intermedio de la grandeza de España, si se atiende a sus rentas anuales —unos 40.000 ducados a fines del siglo XVI ${ }^{54}$ _, importantes especialmente por los grandes beneficios obtenidos de las minas de alumbre de Mazarrón (que llegaron a suponer unos ingresos de 20.000 ducados anuales, la mitad de las riquezas de la casa), compartidas con la casa de Villena, pero que tras un siglo de formidable actividad comercial se vieron cerradas por las guerras de Felipe II contra neerlandeses, ingleses y franceses ${ }^{55}$. Anteriormente el II marqués de los Vélez, Luis Fajardo de la Cueva, había puesto todo su empeño en evitar pagar a seis de sus once hermanos las dotes y alimentos que les correspondían, fracasando en los tribunales, pero dilatando durante años los procesos ${ }^{56}$. Las deudas de la

50 LEMEUNIER y GONZÁLEZ CASTAÑO, 10 (Murcia, 1989): 119-144.

51 VINCENT, 1985: 287-301. ANDÚJAR CASTILLO y BARRIOS AGUILERA, 13 (Alicante, 1996): 85-121.

52 Escrito en 1635, siendo V marqués de los Vélez don Pedro Fajardo Pimentel. MARSILLA DE PASCUAL y BELTRÁN CORBALÁN, 2007.

53 Destacaron tres ramas: los marqueses de Espinardo (título de 1627); los marqueses de San Leonardo (título concedido en 1649); y los señores de Polop, Benidorm y Montealegre (condes de Montealegre en 1706, y marqueses de Albudeite desde 1711). VÁLGOMA Y DÍAZ-VARELA, 1957: 188-201 y 237-242. TORRES FONTES, 4 (Murcia, 1978): 109-175.

54 En 1597-1600 la casa con mayores ingresos era de la Medina Sidonia, con $170.000 \mathrm{du}-$ cados anuales. Otras 36 casas tituladas hispanas tenían rentas similares o superiores los Vélez, mientras que 75 contaban con una riqueza inferior. HENDRIKS, 14 (Barcelona, 1994): 89-90.

55 FRANCO SILVA, 1996. RUIZ MARTÍN, 2005.

56 Carta del príncipe Felipe al Consejo Real sobre el desposorio que don Enrique Enríquez tenía concertado con doña Juana Fajardo. Castellón de Ampurias, octubre de 1548, AGS, Estado, legajo 76, f. 84. Pleito entre Pedro y Gonzalo Fajardo de Silva, hijos de Pedro 
casa se agravarían con la corta privanza real de su heredero, Pedro Fajardo Fernández de Córdoba, III marqués de los Vélez, que perderá la gracia de Felipe II a finales de 1578.

Esto nos lleva a otra idea esencial, que es la orfandad como motivo del debilitamiento del poder de una casa aristocrática, no sólo por la minoría de edad, sino por la falta de un apoyo y guía en la corte ${ }^{57}$. Y es que tras la muerte de su tío-abuelo, el poderoso comendador mayor de Castilla, don Juan de Zúñiga, el IV marqués de los Vélez, a pesar de ser hijastro del VIII conde de Benavente, un personaje influyente del reinado de Felipe III e inicios del de Felipe IV, se vio postergado en la corte y sólo tres años antes de su muerte (en 1628) obtuvo el virreinato de Valencia, una suerte de premio de consolación para el nieto - y heredero- de don Luis de Requesens ${ }^{58}$.

Será en esos momentos de repliegue del tronco principal de los Fajardo a sus estados murcianos, cuando surja con fuerza la casa de Espinardo, rama a la vez segundona y bastarda de los Vélez. Segundona por descender de don Diego Fajardo y Córdoba, el hijo menor del II marqués de los Vélez; y bastarda porque su auténtico fundador fue uno de los militares más sobresalientes del reinado de Felipe III, don Luis Fajardo y Ruíz de Avendaño - almirante de la Mar Océano - espurio del citado marqués. Sin embargo ninguna de esas líneas poseía señoríos ni vínculos destacables ${ }^{59}$, siendo familias de la oligar-

Fajardo, marqués que fue de los Vélez, con Luis Fajardo, marqués de los Vélez y Molina, sobre alimentos, ARChGr, 1552, C. 812, P. 005. Pleito de Luis Fajardo, Marqués de los Vélez, con Yllán Venegas, curador de Luisa, Catalina y María Fajardo y Silva, sobre deudas por alimentos de éstas, situadas sobre alumbres de Mazarrón, juros de Murcia y Lorca y frutos de la encomienda, ARChGr, 1558, C. 2712, P. 7.

57 Situación que contrasta con el apoyo que el marqués de Velada recibió de su tío, el gran duque de Alba, germen de su carrera cortesana. Algo similar sucede con el duque de Lerma, cuyo apoyo encumbró a su sobrino y yerno, el conde de Lemos. MARTÍNEZ HERNÁNDEZ, 2004: 163-178. ENCISO ALONSO-MUÑUMER, 2007: 205-234.

58 El IV marqués de los Vélez se erigió como heredero de su abuelo materno tras pleitear contra su hermano de madre, el I marqués del Villar de Grajanejos. Luis Fajardo de Requesens, marqués de los Vélez, vecino de Valladolid, con Juan de Zúñiga, marqués de El Villar, ARChV, Pleitos Civiles Alonso Rodríguez (D), C. 0248.0001. 0252. 0001. Pleito de tenuta entre el marqués de Villar, Juan de Zúñiga y Pimentel, y el marqués de los Vélez, Luis Fajardo y Requesens, sobre la sucesión en los mayorazgos que fundaron el comendador mayor de Castilla, Juan de Zúniga, su mujer Estefania de Requesens (1546) y Luis de Requesens (1574), SN-AHN, Osuna, C. 3635-3636.

59 La rama segundona aportaba un mayorazgo no excesivamente rico, valorado en 1.800 ducados, fundado por las hijas del II marqués de los Vélez, Francisca y Mencía, a favor de su hermano Diego, quien casó a edad avanzada tras la muerte del primogénito y la minoría de edad de su sobrino, el IV marqués, es decir ante el peligro de desaparición de la casa. Extracto de los testamentos de doña Francisca Fajardo (1579) y doña Mencía Fajardo (1592), SNAHN, Espinardo, C. 4, legajo 9 y 10. 
quía murciana ${ }^{60}$ - los Tenza o Entenza ${ }^{61}$ y los Guevara ${ }^{62}$ - las que aporten la base patrimonial de la casa de Espinardo, segunda que recibió un título nobiliario en el reino de Murcia ${ }^{63}$ (en 1627), tras la de sus parientes mayores, que lo habían hecho ciento veinte años antes. Esto fue debido a sus destacados servicios a la Corona, reconocidos por Felipe IV al conceder el título de vizconde de Monteagudo (1626) y, un año después, el de marqués de Espinar$\mathrm{do}^{64}$. Con ello se premiaba, entre otras cosas, la destacada participación del almirante Juan Fajardo de Tenza ${ }^{65}$ en la recuperación de Bahía a los holandeses, en 1625. La colaboración entre ambas ramas de los Fajardo será muy intensa a inicios del siglo XVII, pues el IV marqués de los Vélez seguía siendo adelantando del reino murciano, recurriendo a sus primos Tenza-Fajardo para ostentar la tenencia del adelantamiento, en momentos de máxima emergencia militar, debido a la expulsión de los moriscos, que tuvo en Cartagena uno de sus puertos clave ${ }^{66}$.

Lo cierto es que los primeros titulares de la casa de Espinardo renuevan la sangre de los Fajardo, no por la unión con segundones de casas tituladas, sino por el patrimonio y los vínculos que reciben de familias de la oligarquía murciana, erigidas en señores de vasallos, pero sin descendientes. Asimismo los Tenza-Fajardo son un epílogo del prestigio militar de los adelantados del reino de Murcia, aunque ahora no son las luchas fronterizas de las Reconquista las que aportan prestigio. A inicios del siglo XVII será el servicio en la armada lo que más contribuya a la política de reputación de Felipe III y el duque de Lerma ${ }^{67}$. Y en esas labores se desempeñará brillantemente el bastardo almirante don Luis Fajardo, luchando contra berberiscos, ingleses y holandeses en el Mediterráneo, el Atlántico y el Caribe. Fue don Luis uno de los más ilustres marinos de la España de su tiempo, junto a Oquendo o Santa Cruz, y sus pasos fueron seguidos por sus dos hijos. El mayor, Alonso Tenza Fajardo,

60 LEMEUNIER, 1998. MONTOJO MONTOJO, 30 (Valladolid, 2010): 119-136.

61 Venta de Pedro Zambrana Fajardo y Manuel Zambrana Guerrero y sus mujeres a Alonso Tenza Pacheco, de las villas de Ontur y Albatana. 14 de octubre de 1598, AHPMu, Prot. 122, f. 563.

62 Testamento de Carlos de Guevara y fundación del mayorazgo de Ceutí, Monteagudo y casas de Murcia. 28 de enero de 1528, AHPMu, Prot. 4030.

63 Los títulos nobiliarios murcianos datan, sobre todo, del siglo XVIII, debido al apoyo a Felipe V durante la Guerra de Sucesión, así como al esplendor económico de la centuria. DOMÍNGUEZ NAFRÍA, 1999: 101-143.

${ }^{64}$ Relación de títulos de vizconde de Monteagudo y marqués de Espinardo, AGS, Cámara de Castilla, Lib. Relación 32, f. 231bis y 273v.

65 Poco antes publicó Francisco Cascales su famoso nobiliario, dedicado a este almirante y no a su primo y pariente mayor, don Luis Fajardo Requesens, IV marqués de los Vélez. CASCALES, 1621.

66 RUIZ IBÁÑEZ, 1995: 268-273. LOMAS CORTÉS, 28 (Barcelona, 2010): 45-70.

67 GARCÍA GARCÍA, 1996. 
fue gobernador de Filipinas; el menor, Juan Fajardo Tenza, fue también almirante y capitán general de Galicia, además de nuevo jefe familiar por la muerte de su hermano ${ }^{68}$.

Tener como fundador de la casa a un ilegítimo no era ninguna mácula para la casa de Espinardo. De hecho fue algo habitual entre las familias más encumbradas, en no pocas ocasiones descendientes de bastardos regios, como fue el caso de los almirantes de Castilla, los duques de Medinaceli o los duques de Villahermosa; así como de bastardos de aristócratas o miembros del alto clero, entre los que se encuentran la casa de Medellín y varias de las ramas surgidas del linaje Mendoza, descendientes del gran cardenal de España: Mondéjar, Mélito y Cenete ${ }^{69}$. La ilegitimidad, a pesar de la deshonra que pudiera suponer, no inhabilitaba para acceder a ningún honor o gracia si se pertenecía a alguna ilustre familia ${ }^{70}$. Mucho más grave era tener ascendencia manchada, es decir conversa, algo también frecuente entre la nobleza, incluida la aristocracia, tal y como recuerdan los tizones y libros verdes ${ }^{71}$, auténticos desmitificadores de la pretendida pureza nobiliaria.

Pronto las dos casas surgidas del linaje Fajardo se separan, no sólo en lo geográfico. Los marqueses de los Vélez recuperan su protagonismo en la gobernación de la Monarquía Hispánica, durante los reinados de Felipe IV y Carlos II ${ }^{72}$. En tanto que sus primos, los marqueses de Espinardo, a partir del II marqués, Diego Ambrosio Fajardo, al perder la varonía del linaje tras su temprana muerte, dejan de destacar por el servicio de las armas que les había encumbrado. Además los lazos familiares y las relaciones de auxilio entre ambas casas se diluyen, perdiendo así relevancia el apellido Fajardo. En el caso de los parientes mayores se extingue la línea de varonía a finales del siglo XVII, pasando sus títulos y posesiones a la casa ducal de Montalto y, finalmente a la de Villafranca. Respecto a los segundones, la unión con familias ajenas al reino de Murcia y con una cierta relevancia económica, como los Guevara, Vera y Zúñiga, posterga tanto el apellido Fajardo como Tenza ${ }^{73}$ entre los sucesivos titulares de la casa de Espinardo ${ }^{74}$; como constancia de ello señalaremos que el noveno marqués, Francisco, ordena de la siguiente manera sus apellidos: Vera, Entenza, Fajardo y Quiñones.

El hecho de no renovar alianzas matrimoniales entre ambas ramas de los Fajardo, así como el alejamiento definitivo de la casa de los Vélez respecto al

68 HERNÁNDEZ FRANCO, 2012.

69 SORIA MESA, 2007: 193. MOREJÓN RAMOS, 2009: 25.

70 HERNÁNDEZ FRANCO y RODRÍGUEZ PÉREZ, 69/232 (Madrid, 2009): 331-362.

71 MENDOZA Y BOBADILLA, 1992. COMBESCURE THIRY, 2003.

72 SÁNCHEZ RAMOS, 24 (Vélez Rubio, 2005): 31-50; 25 (Vélez Rubio, 2006): 19-65.

73 Algo similar ocurre con la casa de Montaos, entre finales del siglo XVI e inicios del XVII, siendo absorbida por la casa condal de Grajal. PRESEDO GARAZO, 2011: 47-58.

74 VÁLGOMA Y DÍAZ-VARELA, 1957: 201 y 211. 
reino de Murcia, desde la década de 1630, implicó la nula colaboración entre los parientes. Las dos casas buscaron su engrandecimiento de forma separada. Por un lado, la casa aristocrática vio como sus titulares ocupaban virreinatos y cargos cortesanos ${ }^{75}$, y de paso trataban de asegurarse la condición de grandes de primera clase, encargando un memorial a Salazar y Castro en 1686, que no llegó a publicarse, quizá porque dicho honor les fue denegado. En esa obra no se ensalzaba a ninguna rama menor de los Fajardo, sino que toda la atención residía en la línea de primogenitura y el enlace con familias aristocráticas y cortesanas, como los Chacón y los Requesens-Zúñiga ${ }^{76}$. Además la cronología elegida acababa en 1520, fecha de la supuesta creación de la grandeza por Carlos V, haber ido más lejos supondría reconocer una grandeza de segunda clase, que ya poseía la casa per se. Mientras que la casa menor, desprovista del prestigio militar de sus fundadores y de la protección de sus parientes mayores, buscó también la grandeza, en un memorial de mediados del siglo XVIII, en el que se pasaba por alto su condición de línea segundogénita de los Fajardo, apostando por los méritos y virtudes de toda la sangre reunida en su seno, principalmente por parte de familias de la nobleza media, fundadoras de mayorazgos y dueñas de señoríos, y sobredimensionando lejanas relaciones con casas de la grandeza de primera clase como Medinaceli, Medina Sidonia, Feria o Benavente ${ }^{77}$.

Quizá ningún otro suceso subraye tan claramente el alejamiento de ambas casas, como el hecho de que en 1687 el VI marqués de los Vélez —el último varón titular de la casa - acuerde su segundo matrimonio con una prima, hija de los condes de Ayala (familia integrada en la aristocracia cortesana), en busca de un heredero que no llegó. Tampoco las tres hijas bastardas que tuvo Fernando Joaquín Fajardo permitían una alternativa sucesoria ${ }^{78}$. Sería su hermana María Teresa Fajardo, VII marquesa, y última con el apellido Fajar-

75 Entre 1631 y 1647 el V marqués de los Vélez será virrey de Valencia, Aragón, Navarra, Cataluña y Sicilia, además de embajador en Roma. Su sucesor será, entre 1666 y 1693 , gobernador de Orán, virrey de Cerdeña y Nápoles, caballerizo mayor de la reina, consejero de Estado, presidente del Consejo de Indias y superintendente general de Hacienda. GUILLAMÓN ÁLVAREZ, F. J. et alii, 2004. MARTINO y RODRÍGUEZ REBOLLO, 2007: 321-335. NICOLÁS MARTÍNEZ, 3 (2011).

76 RODRÍGUEZ PÉREZ y HERNÁNDEZ FRANCO, 2008.

77 Materiales histórico-genealógicos que propone el Marqués de Espinardo, para que vistos, y reconocidos por persona bien versada en semejantes asuntos... los coordinen, y reduzca a méthodo propio de Memorial... les ponga en mano del Rey N. S. y a sus reales pies, puntual noticia, de la Calidad, Méritos y Servicios del Marqués su padre y abuelos, con la muy rendida súplica... le digne y sea $S$. M. servido de concederle al Marqués, sus hijos, descendientes y subcessores en su casa, el honor de la grandeza de Castilla, BNE, Ms. 11.723. f. 26-30.

78 Las tres eran monjas y recibieron algunas rentas de su padre. Testamento de Fernando Joaquín Fajardo Requesens y Zúñiga, VI marqués de los Vélez, AHPM, Prot. 13.703, f. 376v. 
do, la que daría efímera continuidad a la casa de los Vélez, pues solo tuvo una hija, que además tuvo que llevar el apellido paterno (Aragón) ${ }^{79}$. Pero ni antes de las dificultades para continuar la varonía Fajardo por parte de la casa de los Vélez, ni en los momentos en que tal hecho parecía irremediable, a comienzos del siglo XVIII, en ningún caso se contempló la unión con alguna mujer de la casa de Espinardo.

Ciertamente, tras el enlace matrimonial de la primera generación de Espinardos y la tercera de Vélez, habían pasado otras tres generaciones sin nupcias entre ambas familias; y en ello debió influir poderosamente el hecho de que los descendientes de la casa de Espinardo sufrieron una oscurecimiento en su trayectoria social, estuvieron cada vez más alejados de la corte y de un posible acceso a la grandeza. A la postre, se dio una disociación total entre casas, debido a la diferencia de estatus, y no a la hostilidad o deseos de la rama menor de situarse por encima de sus primos. Era imposible que la casa menor de los Fajardo rivalizara en ningún aspecto con la de sus parientes mayores, pues no tenía ni rentas, ni antigüedad en el linaje, ni alianzas matrimoniales tan destacadas como sus parientes mayores; y tampoco pudo auparse al mismo grupo social (el de la aristocracia cortesana), tal y como sucedió desde fines de la Edad Media con las ramas segundonas surgidas de los principales linajes castellanos.

\section{CONCLUSIÓN}

En definitiva, lo que se quiere señalar es que la trayectoria de las dos casas, que conocemos bien a través de dos prestigiosos genealogistas como Luis de Salazar y Castro y Juan Alonso Guerra ${ }^{80}$ - en el caso de los Espinardo-, no deja dudas de que el origen y el parentesco amplio que representa el linaje, aun sin desaparecer, pierde peso ante hechos que son relacionables preferentemente con la casa como son las rentas, la capacidad propia y señera de representación y distinción - lo que le llevó a seleccionar interesadamente a los parientes y ancestros - y un tamaño de las relaciones familiares para cuestiones de patronazgo y auxilio en el que las líneas del parentesco apenas sobrepasan los lazos paternos-filiales, a los que se puede unir también los agregados domésticos y una parte de los vasallos de sus señoríos.

Así pues, tras analizar densa y longitudinalmente al linaje Fajardo y a sus dos casas, estudios que se pueden completar con lo que ya sabemos sobre otros linajes bifurcados en casas como son los Fernández de Córdoba, los Toledo, los Zúñiga, los Manrique, los Pacheco-Girón, los Mendoza o los Silva, y sin que

79 SÁNCHEZ RAMOS, 25 (Vélez Rubio, 2006): 58.

80 PIFERRER, 1859, vol. 5: 178. ANDRÉS, 187/3 (Madrid, 1990): 373-402. 
esto sea una axioma general para todas las familias aristocráticas de Castilla, sí se puede afirmar que la idea y práctica de linaje — paulatinamente - decae y se diluye, en tanto que se adopta por parte de aristócratas, como estaba ocurriendo también en el resto de la Europa occidental, una forma de organización familiar, pero con repercusión a nivel de sociedad, como es la casa. No se percibió que la misma podía ser contraria a la reproducción o conservación de grandes unidades de parentesco extenso, que fácilmente podían suplir la desaparición de la línea troncal haciendo ocupar esta posición a la colateral más próxima, y ejercía un amplio control sobre todos ellos, como también de auxilio y protección, a través del pariente mayor. Si las casas reemplazaron a los linajes, el éxito de su implantación se encontraba, entre otras razones, en que permitía adaptarse a una época de cambio dentro del grupo nobiliario en el que la dependencia de la casa real fue en aumento; en que se produjo la aparición de nuevas vías de acceso a la nobleza y, en consecuencia, la rama que recibía la gracia real podía desgajarse del linaje primigenio; $y$, por último, en un sentido más próximo de parentesco y obligaciones en torno al mismo, que nos sitúan ante una familia de parentesco estrecho y reducido a las primeros vínculos familiares. Castilla y su sociedad se modernizaban, sin percibir entonces, pues no era su propósito, que también estaba resquebrajándose una forma de organización socio-política de comunidades y grupos de privilegio y jerarquías, que acabaría destruyendo el individualismo aristocrático-burgués en el siglo XIX ${ }^{81}$.

\section{BibLIOGRAFíA}

Álvarez-Ossorio Alvariño, Antonio, «El arte de medrar en la corte: rey, nobleza y el código del honor», en Francisco Chacón Jiménez y Juan Hernández Franco (eds.), Familias, poderosos y oligarquías, Murcia, Universidad de Murcia, 2001; 39-60.

Álvarez-Ossorio Alvariño, Antonio, «Las esferas de la Corte: príncipe, nobleza y mudanza en la jerarquía», en Francisco Chacón Jiménez y Nuno Gonçalo Monteiro (eds.), Poder y movilidad social: cortesanos, religiosos y oligarquias en la península Ibérica (siglos XV-XIX), Madrid, CSIC, 2006; 129-180.

Andrés, Gregorio de, «La biblioteca nobiliaria de Juan Alfonso Guerra, rey de armas de Felipe V, en la Biblioteca Nacional», Boletín de la Real Academia de la Historia, 187/3 (Madrid, 1990): 373-402.

Andújar Castillo, Francisco, «Las comunidades en el Reino de Murcia: la tercera voz», en Juan Luis Castellano Castellano y Francisco Sánchez-Montes González (coords.), Carlos V. Europeísmo y Universalidad. Población, economía y sociedad. La organización del poder, vol. 2, Madrid, SECCFC, 2001; 43-62.

81 IGLESIAS, 1991. 
Andújar Castillo, Francisco y Barrios Aguilera, Manuel, «El arte de usurpar. Señores, moriscos y cristianos viejos en el marquesado de los Vélez (1567-1568)», Sharq al-Andalus, 13 (Alicante, 1996): 85-121.

Arce de Otálora, Juan, De nobilitatis, immunitatis Hispaniaecausis (quas hidalguia appellant) de que Regaliũ tributorũ (quos pechos dicunt) iure, ordine, iudicio, \& excusation e summa, seu tractatus, Granada, Sancho y Sebastián de Nebrija, 1553.

Atienza Hernández, Ignacio, Aristocracia, poder y riqueza en la España moderna. La Casa de Osuna, siglos XV-XIX, Madrid, Siglo XXI, 1987.

Atienza Hernández, Ignacio y Simón López, Mina, «"Aunque fuese con una negra si S.M. así lo desea": Sobre la autoridad real, el amor y los hábitos matrimoniales de la nobleza hispana», Gestae. Taller de Historia, 1 (Murcia, 1989): 31-52.

Azevedo, Alfonso, Commentarii iuris civilis in Hispaniae Regiae Constitutiones, Madrid, Francisco de Robles, 1602.

Beceiro Pita, Isabel, «La conciencia de los antepasados y la gloria del linaje en la Castilla bajomedieval», en Reina Pastor (comp.), Relaciones de poder, de producción y parentesco en la Edad Media y Moderna, Madrid, CSIC, 1990; 329-349.

Beceiro Pita, Isabel, El condado de Benavente en el siglo XV, Benavente, Centro de Estudios Benaventanos Ledo del Pozo, 1998.

Beceiro Pita, Isabel, «La legitimación del linaje a través de los ancestros», en Jon Fernández de Larrea y Rojas y José Ramón Díaz de Durana Ortiz de Urbina, Memoria e Historia: utilización política en la Corona de Castilla al final de la Edad Media, Madrid, Sílex, 2010; 77-100.

Beceiro Pita, Isabel y Córdoba de la Llave, Ricardo, Parentesco, poder y mentalidad. La nobleza castellana: siglos XII-XV, Madrid, CSIC, 1990.

Benigno, Francesco, La sombra del rey. Validos y lucha política en la España del siglo XVII, Madrid, Alianza, 1992.

Bourquin, Laurent, La noblesse dans la France Moderna (XVI $I^{e} X V I I I^{e}$ siècles), Paris, Belin, 2002.

Carrasco Martínez, Adolfo, «Herencia y virtud. Interpretaciones e imágenes de lo nobiliario en la segunda mitad del siglo XVI», en Luis Antonio Ribot García y Ernest Belenguer Cebrià (coords.), Las sociedades ibéricas y el mar a finales del siglo XVI, vol. 4, Madrid, SECCFC, 1998; 231-271.

Carrasco Martínez, Adolfo, «Elementos del debate europeo. En torno a la idea de nobleza alrededor de 1600. Apuntes sobre la discusión en Italia», en Manuel Rivero Rodríguez (coord.), Nobleza Hispana, Nobleza Cristiana: la orden de San Juan, 1, Madrid, Polifemo, 2009; 135-147.

Carrasco Martínez, Adolfo, El poder de la sangre. Los duques del Infantado, Madrid, Actas, 2010.

Carriazo Rubio, Juan Luis, La memoria del linaje. Los Ponce de León y sus antepasados a fines de la Edad Media, Sevilla, Universidad de Sevilla y Ayuntamiento de Marchena, 2002. 
Cascales, Francisco, Discursos Históricos de la Muy Noble y Muy Leal Ciudad de Murcia y su Reino, Murcia, Luis de Beros, 1621.

Clavero, Bartolomé, Mayorazgo. Propiedad feudal en Castilla (1369-1836), Madrid, Siglo XXI, 1974.

Combescure Thiry, Monique (ed.), El libro verde de Aragón, Zaragoza, Certeza, 2003.

Cooper, Edward, «La revuelta de las Comunidades. Una visión desde la sacristía», Hispania, 56/193 (Madrid, 1996): 467-495.

Cunha, Mafalda Soares da, A Casa de Bragança (1560-1640). Práticas Senhoriais e Redes Clientelares, Lisboa, Estampa, 2000.

Cunha, Mafalda Soares da, «Estratégias matrimonias da Casa de Bragança e o casamento do duque D. João II», Hispania, 64/216 (Madrid, 2004): 39-62.

Cunha, Mafalda Soares da y Monteiro, Nuno Gonçalo, «Aristocracia, Poder e Família em Portugal, Séculos XV-XVIII», en Mafalda Soares da Cunha y Juan Hernández Franco (orgs.), Sociedade, Família e Poder na Península Ibérica. Elementos para uma história comparativa, Évora y Murcia, Universidade de Évora y Universidad de Murcia, 2010; 47-75.

Dewald, Jonathan, La nobleza europea, Valencia, Pre-Textos, 2004.

Domínguez Nafría, Juan Carlos, «La nobleza del Reino de Murcia», en Carmen Iglesias (dir.), Nobleza y sociedad en la España moderna III. Las Noblezas españolas, reinos y señoríos en la Edad Moderna, Oviedo, Nobel, 1999; 101-143.

Domínguez Ortiz, Antonio, Las clases privilegiadas del Antiguo Régimen, Madrid, Istmo, 1973.

Donati, Claudio, L'idea di nobiltà in Italia: secoli XIV-XVIII, Roma, Laterza, 1995.

Elliott, John H., El conde-duque de Olivares. El político en una época de decadencia, Barcelona, Crítica, 1990.

Elliott, John H. y Brockliss, Laurence W. B. (eds.), The World of the Favourite, New Haven-Londres, Yale University Press, 1999.

Enciso Alonso-Muñumer, Isabel, Nobleza, poder y mecenazgo en tiempos de Felipe III: Nápoles y el conde de Lemos, Madrid, Actas, 2007.

Franco Silva, Alfonso, El alumbre del Reino de Murcia. Una historia de ambición, intrigas, riqueza y poder, Murcia, Real Academia Alfonso X el Sabio, 1996.

García de Saavedra, Juan, Tractatus de hispaniorum nobilitates et exemptione suie ad pragmatican cordubensem quae est I 8. II lib.2. novae recopilat, Madrid, Viuda de Fernando Correa, 1622.

García García, Bernardo José, La Pax Hispánica: política exterior del Duque de Lerma, Lovaina, Universidad de Lovaina, 1996.

García García, Bernardo José, «La aristocracia y el arte de la privanza», Historia Social, 28 (Valencia, 1997): 113-125.

García Hernán, David, «Genealogías de nobles en la España moderna», Revista de Historiografia, 15 (Madrid, 2011): 28-38. 
Grace, Philip, «Family and familiars. The concentric household in late medieval penitentiary petitions», Journal of Medieval History, 35/2 (Southampton, 2009): 189-203.

Grassby, Richard, Kinship and Capitalism: Marriage, Family, and Business in the English Speaking World, 1580-1720, Londres, Cambridge University Press, 2001.

Guardiola, Juan Benito, Tratado de nobleza, y de los títulos y ditados que oy día tienen los varones claros y grandes de España, Madrid, Viuda de Alonso Gómez, 1591.

Guillamón Álvarez, Francisco Javier et alii, Gli Eroi Fassardi. Los Héroes Fajardos. Movilización social y memoria política en el Reino de Murcia (ss. XVI al XVIII), Murcia, Real Academia Alfonso X el Sabio, 2004.

Guillén Berrendero, José Antonio, La idea de nobleza en Castilla durante el reinado de Felipe II, Valladolid, Universidad de Valladolid, 2007.

Gutiérrez, Juan, Practicarum quaestionum civilium, Colonia, Perachon \& Cramer, 1730.

Hendriks, R., «El patrimonio de don Luis de Requesens y Zúñiga (1528-1576. ¿Fue don Luis de Requesens y Zúñiga (1528-1576) pobre o rico?», Pedralbes, 14 (Barcelona, 1994): 81-92.

Hernández Franco, Juan, Al servicio del mayor Rey de La Tierra: el linaje de Luis Fajardo, capitán general de la Mar Océano (ss. XVI-XVII), Murcia, Real Academia Alfonso X el Sabio, 2012.

Hernández Franco, Juan y Jiménez Alcázar, Juan Francisco, «Estado, aristocracia y oligarquías urbanas en Murcia. Un punto de flexión en torno a las Comunidades de Castilla», Chronica Nova, 23 (Granada, 1996): 171-187.

Hernández Franco, Juan y Molina Puche, Sebastián, «Aristocracia, familia-linaje, mayorazgo: la casa de los marqueses de Villena en la Edad Moderna», Historia Social, 66 (Valencia, 2010): 3-22.

Hernández Franco, Juan y Rodríguez Pérez, Raimundo A., «Bastardía, aristocracia y órdenes militares en la Castilla moderna: el linaje Fajardo», Hispania, 69/232 (Madrid, 2009): 331-362.

Hernando Sánchez, Carlos José, Castilla y Nápoles en el siglo XVI. El virrey Pedro de Toledo: linaje, estado y cultura (1532-1553), Valladolid, Junta de Castilla y León, 1994.

Heusch, Carlos, «La pluma al servicio del linaje. El desarrollo de los nobiliarios en la Castilla trastámara», e-Spania [en línea]. 11 (2011). Disponible en:

http://e-spania.revues.org/20313 [consultado el 5 de junio de 2012]

Iglesias, Carmen, Individualismo noble, Individualismo burgués: libertad y participación política en el liberalismo francés del siglo XVIII, Madrid, Real Academia de la Historia, 1991.

Jiménez Moreno, Agustín, «En búsqueda de una nobleza de servicio. El Conde Duque de Olivares, la aristocracia y las Órdenes Militares (1621-1643)», en Manuel Rivero Rodríguez (coord.), Nobleza Hispana, Nobleza Cristiana: la orden de San Juan, vol. 1, Madrid, Polifemo, 2009; 209-256. 
Keniston, Hayward, Francisco de los Cobos, secretario de Carlos V, Madrid, Castalia, 1980 ( $1^{\mathrm{a}}$ edición 1959).

Kettering, Sharon, Patrons, Brokers, and Clients in Seventeenth-Century France, Oxford, Oxford University Press, 1986.

Kettering, Sharon, «Patronage and Kinship in Early Modern France», French Historical Studies, 16/2 (Tempe, 1989): 408-435.

Kettering, Sharon, «The Household Service of Early Modern French Noblewomen», French Historical Studies, 20 (Tempe, 1997): 55-85.

Kettering, Sharon, French Society, 1589-1715, Londres, Longman, 2001.

Kettering, Sharon, «Household appointments and dismissals at the court of Louis XIII», French History, 21/3 (Oxford, 2007): 269-288.

Ladero Quesada, Miguel Ángel, Los señores de Andalucía. Investigaciones sobre nobles y señoríos en los siglos XIII a XV, Cádiz, Universidad de Cádiz, 1998.

Lemeunier, Guy, Los señoríos murcianos (s. XVI-XVIII), Murcia, Universidad de Murcia, 1998.

Lemeunier, Guy y González Castaño, Juan, «Señores y oligarcas. Las luchas políticas en Mula durante los siglos XVI y XVII», Áreas, 10 (Murcia, 1989): 119-144.

Lomas Cortés, Manuel, «El marqués de los Vélez y el desarme de los moriscos de Murcia (1601-1605)», Manuscrits, 28 (Barcelona, 2010): 45-70.

Marañón, Gregorio, Los Tres Vélez. Una historia de todos los tiempos, Almería, Instituto de Estudios Almerienses, 2005 ( $1^{\mathrm{a}}$ edición 1960).

Maravall, José Antonio, Estado Moderno y Mentalidad Social, Madrid, Alianza Editorial, 1986.

Marsilla de Pascual, Francisco Reyes y Beltrán Corbalán, Domingo (eds.), Libro Becerro de la Casa y Estados de los Vélez, Murcia, Fundación Séneca, 2007.

Martínez Hernández, Santiago, El Marqués de Velada y la Corte en los reinados de Felipe II y Felipe III. Nobleza cortesana y cultura política en la España del Siglo de Oro, Salamanca, Junta de Castilla y León, 2004.

Martino, Aurora y Rodríguez Rebollo, Patricia, «Fernando Joaquín Fajardo, marqués de los Vélez, virrey de Nápoles (1675-1683), en Francisco Andújar Castillo y Julián Pablo Díaz López (coords.), Los señoríos en la Andalucía Moderna. El Marquesado de los Vélez, Almería, Instituto de Estudios Almerienses, 2007; 321-335.

Mendoza y Bobadilla, Francisco, El tizón de la nobleza española: o máculas y sambenitos de sus linajes, Madrid, Colegio Heráldico de España y de las Indias, 1992 ( $1^{\mathrm{a}}$ edición 1560$)$.

Mestres, Kate, The English Noble Household 1250-1600, Oxford, Blackwell, 1988.

Mexía, Fernando, Libro titulado Nobiliario perfectamente compilado y ordenado por el onrrado cavallero Fernando Mexía veynte quatro de Jahén, Sevilla, Juan Gentil y Pedro Brum, 1492.

Minguito Palomares, Ana, Linaje, poder y cultura. El gobierno de Íñigo Vélez de Guevara, VIII conde de Oñate, en Nápoles (1648-1653), tesis doctoral, Universidad Complutense de Madrid, 2002. 
Molas Ribalta, Pere, «Los marqueses de Camarasa. Familia, jerarquía y poder», en Juan Jesús Bravo Caro y Juan Sanz Sampelayo (eds.), IX Reunión Científica de la Fundación Española de Historia Moderna. Población y grupos sociales en el Antiguo Régimen, vol. 1, Málaga, Universidad de Málaga, 2009; 147-162.

Molina Puche, Sebastián y Ortuño Molina, Jorge, Los grandes del reino de Murcia. Los Marqueses de Villena: caída y auge de una casa aristocrática, Murcia, Real Academia Alfonso X el Sabio, 2009.

Molina Recio, Raúl, La nobleza en la España moderna: los Fernández de Córdoba. Familia, riqueza, poder y cultura, tesis doctoral, Universidad de Córdoba, 2004.

Monteiro, Nuno Gonçalo, «Casa e Linhagem: o vocabulário aristocrático em Portugal nos séculos XVII e XVIII», Penélope. Fazer e Desfazer a História, 12 (Lisboa, 1993): 43-63.

Monteiro, Nuno Gonçalo, «Nobility and aristocracy in Ancien Régime Portugal (Seventeenth to Nineteenth centuries)», en Hamish Scott (ed.), The European nobilities in the Seventeenth and Eighteenth centuries, Londres, Longman, 1995; 256-284.

Monteiro, Nuno Gonçalo, O Crepúsculo dos Grandes. A Casa e o Património da Aristocracia em Portugal (1750-1834), Lisboa, INCM, 1998.

Monteiro, Nuno Gonçalo, «Noblesse et aristocratie au Portugal sous 1'Ancien Régime (XVIIe-début du XIXe siècle)», Revue d'histoire Moderne et Contemporaine, 46/1 (París, 1999): 185-210.

Monteiro, Nuno Gonçalo, «Trajectórias sociais e formas familiares: o modelo de sucessão vincular», en Francisco Chacón Jiménez y Juan Hernández Franco (eds.), Familias, poderosos y oligarquías, Murcia, Universidad de Murcia, 2001; 17-37.

Monteiro, Nuno Gonçalo, Elites e Poder. Entre o Antigo Regime e o Liberalismo, Lisboa, ICS, 2007.

Montojo Montojo, Vicente, «Aproximación al estudio de los señores de vasallos murcianos en la Edad Moderna», Investigaciones Históricas, 30 (Valladolid, 2010): 119-136.

Morejón Ramos, José Alipio, Nobleza y humanismo. Martín de Gurrea y Aragón. La figura cultural del IV duque de Villahermosa (1526-1581), Zaragoza, Institución Fernando el Católico, 2009.

Moreno de Vargas, Bartolomé, Discursos de la nobleza de España, Madrid, María de Quiñónez, 1636.

Negre Pastell, Pelayo, «El linaje de Requesens», Anales del Instituto de Estudios Gerundenses, 10 (Gerona, 1955): 25-148.

Nicolás Martínez, María del Mar, «La colección de escultura y orfebrería de don Fernando Joaquín Fajardo, Marqués de los Vélez y Virrey de Nápoles (1675-1683)», OADI. Rivista dell'Osservatorio per le Arti Decorative in Italia [en línea]. 3 (2011). Disponible en: http://www.unipa.it/oadi/oadiriv/?page_id=836 [consultado el 4 de agosto de 2012] 
Owens, John B., Rebelión, monarquía y oligarquía murciana en la época de Carlos $V$, Murcia, Universidad de Murcia, 1980.

Palencia Herrejón, Juan Ramón, «Estrategia patrimonial y jerarquía del linaje: los mayorazgos de la casa ducal de Maqueda en el siglo XVI», Historia, Instituciones y Documentos, 29 (Sevilla, 2002): 337-356.

Pérez de Herrasti, Juan Francisco de Paula, Historia de la Casa de Herrasti, señores de Domingo Pérez, Granada, Universidad de Granada, 2007 (Introducción, edición e índice de María Julieta Vega García-Ferrer. Estudio preliminar Enrique Soria Mesa).

Piferrer, Francisco, Nobiliario de los reinos y señoríos de España, vol. 5, Madrid, Imprenta Eusebio Aguado, 1859.

Presedo Garazo, Antonio, Nobleza y régimen señorial en Galicia. La Casa de Montaos en los siglos XVI y XVII, Santiago de Compostela, Universidad de Santiago de Compostela, 2011.

Quintanilla Raso, María Concepción, «Los grandes linajes. Una investigación histórica sobre el linaje Fernández de Córdoba», en Carmen Iglesias (dir.), Nobleza y sociedad en la España Moderna, Oviedo, Nobel, 1996; 79-110.

Quintanilla Raso, María Concepción, «El engrandecimiento nobiliario en la Corona de Castilla. Las claves del proceso a finales de la Edad Media», en Ídem (dir.), Títulos, Grandes del reino y Grandeza en la sociedad política, Madrid, Sílex, 2006; 19-100.

Quintanilla Raso, María Concepción, «Reproducción y formas de transmisión de los grandes linajes y casa nobiliarias en la Castilla tardomedieval», en Francisco Javier Lorenzo Pinar (ed.), La Familia en la Historia, Salamanca, Universidad de Salamanca, 2009; 89-120.

Rodríguez Llopis, Miguel, «Poder y parentesco en la nobleza santiaguista del siglo XV», Noticiario de Historia Agraria, 12 (Murcia, 1996): 55-90.

Rodríguez Pérez, Raimundo A., El camino hacia la corte. Los marqueses de los Vélez en el siglo XVI, Madrid, Sílex, 2011.

Rodríguez Pérez, Raimundo A. y Hernández Franco, Juan, Memorial de la calidad y servicios de la Casa de Fajardo, marqueses de los Vélez. Obra inédita del genealogista Salazar y Castro. Estudio crítico y edición, Murcia, Real Academia Alfonso X el Sabio, 2008.

Ruiz Ibáñez, José Javier, Las dos caras de Jano. Monarquía, ciudad e individuo, Murcia 1588-1648, Murcia, Universidad de Murcia, 1995.

Ruiz Martín, Felipe, Los alumbres españoles: un índice de la coyuntura económica europea en el siglo XVI, Madrid, Bornova, 2005.

Salazar de Mendoza, Pedro, Origen de las dignidades seglares de Castilla y León: con relación summaria de los reyes de estos reynos, de sus actiones, casamientos, hijos, muertes, sepulturas: de los que las han creado y tenido y de muchos ricos homes confirmadores de priuilegios, Madrid, Imprenta Real, 1657. 
Salvado, João Paulo, «An Aristocratic Economy in Portugal in the First Half of the Seventeenth Century: The House of the Marquises of Castelo Rodrigo», E-journal of Portugese History [en línea]. 9/2 (2011). Disponible en: http://www.brown.edu/ Departments/Portuguese_Brazilian_Studies/ejph/html/issue18/html/v9n2a02.html [consultado el 21 de septiembre de 2012]

Sánchez Ramos, Valeriano, «Sangre, honor y mentalidad nobiliaria: la casa Fajardo entre dos siglos», Revista Velezana, 24 (Vélez Rubio, 2005): 31-50.

Sánchez Ramos, Valeriano, «El poder de una mujer en la Corte: la V Marquesa de los Vélez y los últimos Fajardo (segunda mitad del s. XVII)», Revista Velezana, 25 (Vélez Rubio, 2006): 19-65.

Severim de Faria, Manoel, Noticias de Portugal, Valladolid, Maxtor, 2010 (1 ${ }^{\mathrm{a}}$ edición 1655).

Soria Mesa, Enrique, «La grandeza de España en la Edad Moderna. Revisión de un mito historiográfico», en J. L. Castellano Castellano y F. Sánchez-Montes González (coords.), Carlos V. Europeísmo y Universalidad. Población, economía y sociedad, vol. 4, Madrid, SECCFC, 2001; 619-636.

Soria Mesa, Enrique, La nobleza en la España moderna. Cambio y continuidad, Madrid, Marcial Pons, 2007.

Soria Mesa, Enrique, «La nobleza en la España moderna. Presente y futuro de la investigación», en María José Casaus Ballester (coord.), El Condado de Aranda y la nobleza española en el Antiguo Régimen, Zaragoza, Institución Fernando el Católico, 2009; 213-241.

Stone, Lawrence, Familia, sexo y matrimonio en Inglaterra (1500-1800), México, Fondo de Cultura Económica, 1989.

Terrasa Lozano, Antonio, La Casa de Silva y los duques de Pastrana. Linaje, contingencia y pleito en el siglo XVII, Madrid, Marcial Pons, 2012.

Tomás y Valiente, Francisco, Los validos en la monarquía española del siglo XVII, Madrid, Siglo XXI, 1982.

Torres Fontes, Juan, Don Pedro Fajardo, Adelantado Mayor del Reino de Murcia, Madrid, CSIC, 1953.

Torres Fontes, Juan, «Los Fajardo en los siglos XIV y XV», Miscelánea Medieval Murciana, 4 (Murcia, 1978): 109-175.

Válgoma y Díaz-Varela, Dalmiro de la, Los Saavedra y los Fajardo en Murcia. Nobiliario, Vigo, Academia Alfonso X el Sabio, 1957.

Vincent, Bernard, «Un ejemplo de corso berberisco-morisco: el ataque de Cuevas de Almanzora, 1573», en Vincent, Bernard, Andalucía en la Edad Moderna: economía y sociedad, Granada, Diputación Provincial de Granada, 1985; 287-301.

Recibido: $15 / 10 / 2012$

Aprobado: 01/04/2013 